\title{
A Review on Search and Discovery Mechanisms in Social Networks
}

\author{
Shabnam Hassanzadeh Sharif \\ Department of Computer Engineering, East Azarbaijan Science and \\ Research Branch, Islamic Azad University, Tabriz, Iran, \\ sh.hassanzadeh@iauasrb.ac.ir \\ Shabnam Mahmazi \\ Department of Computer Engineering, East Azarbaijan Science and \\ Research Branch, Islamic Azad University, Tabriz, Iran, \\ sh.mahmazi@iauasrb.ac.ir \\ *Nima Jafari Navimipour \\ Department of Computer Engineering, East Azarbaijan Science and \\ Research Branch, Islamic Azad University, Tabriz, Iran, \\ n.jafari@srbiau.ac.ir \\ Behzad Farid Aghdam \\ Department of Computer Engineering, East Azarbaijan Science and \\ Research Branch, Islamic Azad University, Tabriz, Iran, \\ b.faridaghdam@iauasrb.ac.ir
}

\begin{abstract}
Social search is a variant of information retrieval where a document or website is considered relevant if individuals from the searcher's social network have interacted with it. To the best of our knowledge, there is no new detailed paper which covers discovery method in social network; therefore, in this paper we surveyed searching methods in social network which have been presented so far. We classified the existing methods in four main categories: people search, job search, keyword search and web service discovery. Also we conclude the paper with some implications for future research and practice.
\end{abstract}

Index Terms - Social network, search, discovery, peerto-peer, distributed algorithm, scalability.

\section{Introduction}

Social networks are increasingly attracting the attention of people all around the world by their powerful communications [1]. Social network sites such as MySpace ${ }^{1}$, Facebook ${ }^{2}$, Twitter ${ }^{3}$, LinkedIn $^{4}$ and etc. have millions of users, many of whom have integrated these sites into their daily lives[2, 3]. Most sites support the maintenance of pre-existing social networks but others help people connect based on shared interests or activities, also social networks incorporate new

\footnotetext{
${ }^{1}$ www.myspace.com

${ }^{2}$ www.facebook.com

${ }^{3}$ www.twitter.com

${ }^{4}$ www.linkedIn.com
}

information and communication tools, such as mobile connectivity, blogging and photo/video sharing[1].

The main challenging issues in social networks are: social graph analysis[4, 5], social media search and management[6-8], exploiting social graphs[9, 10], identity algorithms[11,12], mobile social network[1315], social ranking and opinion sites[16, 17], business and social networking[18,19], architectures for open and federated social network platforms[20, 21], social search and discovery [22-29].

This paper aims to search through web services to discover and identify the research challenges that emerge from the social network reality.

In this paper; we first discussed about keyword search and we analyzed two methods namely heap union and T-DHT. The first one efficiently allows users to process a large number of author lists while skipping over irrelevant documents which helps increase the searching time[30]. The latter is T-DHT which has been devised to build a scalable infrastructure for social applications; it can be applied to solve more general Peer-to-Peer keyword search problems[31]. Then we surveyed about people search using two methods, context based search in which the authors propose to leverage the query contexts information with the potential interactions between the targeted person and such context labels to tackle the people search in a social network[32] and SNbased personalized social search which focuses on the search results by considering their relationships to users who belong to the searcher's social network[33]. In the end, we studied four methods for service discovery in social network; LinkedWS, Social Networks for Web Services Discovery, Composite Web Service Builder 
Algorithm and social network-driven framework[6]. We compared these methods and surveyed about all of them.

The remainder of this paper is organized as follows: In section 2 we describe keyword search in general. In section 3, we provide background information about people search in social network. In section 4, we present the discovery of web services. In section 5 , we discuss about the advantages and disadvantages of previous sections. In section 6 , we discuss the open issues and conclusions of our survey.

\section{Keyword Search in Social Network}

Nowadays for sharing and collaboration in social network applications, new ways are needed to publish and search a big amount of objects such as people, videos, jobs and etc. Currently, social application which is one of them allows the association of a set of userdefined keywords named tags to search them by using subset of these tags for retrieval, when publishing these objects. To accomplish this purpose Mozo, A. and J. Salvachúa used a hybrid unstructured-structured algorithm called T-DHT[34] to cope with high demanding requirements. Recent research community proposals preclude a wide Internet deployment due to the emergence of scalability (scalability is one of the important issues in any searching mechanism that defines the ability of a searching mechanism to handle a growing amount of network with predefined level of efficiency [35]) and hot spot problems in the nodes. Although T-DHT has been devised to build a scalable infrastructure for social applications it can be applied to solve more general Peer-to-Peer keyword search problems. T-DHT algorithm is the solution in the keyword search topic plus its clear advantages versus typical inverted index solutions have not been adopted until now in Peer-to-Peer area: (a) the authors can search using conjunctive tag predicates without the need to generate explicit inverted index, because of the stored object tag information in a new and innovative way inside the node links; (b) there is no need to do a postjoin operation in the source node in order to get fulfilling results and, consequently, no huge amount of response traffic is generated towards the source node because T-DHT nodes only send the object references to the source node fulfilling the tag conjunction constraint; (c) no hot spot problems appear even when very popular tags are attached to objects, because the popular tag information is not centralized in any node, but is spread among all the node links; (d) enforcing in the hot spot problem avoidance, when objects search is done using conjunctions of popular tags, the T-DHT search response is fully balanced and scalable and performs identically to using conjunctions of random frequency tags as our simulations have demonstrated. This result has a great importance because T-DHT guarantees a fully balanced behavior despite the unbalanced nature of search queries but this algorithm should be examined in a real Peer-to-Peer environment to contrast the previously obtained simulations results and to verify the system scalability and balanced behavior of T-DHT in a real test bed. The simulation results show T-DHT performs in a fully balanced and scalable way, without generating typical hot spot problems even if unbalanced distributions of popular tags are used [31].

Keyword search provides a simple interface for exploring the content as the accumulation of data in social networks grows. In another paper about keyword search the authors presented a workload-aware keyword search system with access control based on a social network. Authors make two technical contributions: (1) Heap Union, a novel union operator that improves processing of search queries with access control by up to a factor of two and (2) highly accurate cost models that vary in sophistication and accuracy; these cost models provide input to an optimization algorithm that selects the most efficient organization of access control metadata for a given workload. Heap Union which efficiently allows users to process a large number of author lists while skipping over irrelevant documents increase the searching time[30].

As a summary, in this section we go through two methods, one of which is Heap Union that efficiently allows users to process a large number of author lists while skipping over irrelevant documents increasing the searching time[30]. The other one is T-DHT algorithm which not only solves hot spot problem in keyword search but also guarantees a fully balanced behavior in spite of the unbalanced nature of search queries and confirms system scalability in a real situation[31].

\section{TABLE 1. KEYWORD SEARCH MECHANISMS}

\begin{tabular}{|c|c|c|c|}
\hline $\begin{array}{c}\text { Mechanis } \\
\mathbf{m}\end{array}$ & Main idea & $\begin{array}{c}\text { Advantage } \\
\text { s }\end{array}$ & $\begin{array}{c}\text { Disadvantage } \\
\text { s }\end{array}$ \\
\hline Heap union & $\begin{array}{c}\text { Provides } \\
\text { accurate } \\
\text { cost } \\
\text { models of } \\
\text { the query } \\
\text { operators }\end{array}$ & $\begin{array}{c}\text { Improves } \\
\text { query } \\
\text { processing } \\
\text { efficiency. }\end{array}$ & $\begin{array}{c}\text { Queries } \\
\text { update wastes } \\
\text { a lot of time. }\end{array}$ \\
\hline $\begin{array}{c}\text { T-DHT } \\
\text { algorithm }\end{array}$ & $\begin{array}{c}\text { Solves hot } \\
\text { spot and } \\
\text { keyword } \\
\text { search } \\
\text { problems }\end{array}$ & $\begin{array}{c}\text { Makes the } \\
\text { system } \\
\text { fully } \\
\text { scalable. }\end{array}$ & $\begin{array}{c}\text { Implementatio } \\
\text { n is only } \\
\text { based on } \\
\text { computation. }\end{array}$ \\
\hline \multicolumn{3}{|c|}{} \\
\hline
\end{tabular}

\section{People Search in Social Network}

In online social networking services, there are a range of scenarios in which users want to search a particular person given the targeted person's name. The challenge of such people search is namesake, which means that there are many people possessing the same names in the social network. The goal of this method is to return a ranking list of people who possess the targeted name label and connects to other context labels in the social network. The authors consider the interactions among query labels to propose a grouping-based method to solve the context-based people search. This method 
consists of three major sections. First, modeling nodes with query labels are able to reduce the search space to enhance the time efficiency. Second, identifying three different kinds of connectors which connecting different groups, and to exploit connectors to find the corresponding detailed graph topology from the group graph. Third, proposing a Connector-Steiner Tree algorithm to retrieve a resulting ranked list of individuals who possess the targeted label. In online social networking, services such as Facebook, Twitter and LinkedIn, it is essential to provide people search which searches for an individual by name. However, if the query name is a namesake, especially if there exist millions of individuals sharing the query name, it would be difficult to find the target person over social networking services. The authors propose to leverage the query contexts information with the potential interactions between the targeted person and such context labels to tackle the people search in a social network. The idea of the proposed context-based social search is illustrated by Figure 1. Each person is associated with labels, where some have many labels and others provide few labels or only their usernames (e.g., Angel). It can be observed that there are three people named Sam and two named Mary. The weights on the edges indicate the communication cost between two people. Higher weights indicate that the people tend to have a casual acquaintance, whereas lower values imply that they are more familiar with one another. If someone seeks to find a friend named "Mary" who has a friend named George and a colleague familiar with Java, the expected result by our context-based people search and individual search is "Mary-1," rather than "Mary2." Another example is to find an individual named "Sam" who had learned the "C++" programming language with his old friend "Robert" in his hometown "Boston", the expected target would be "Sam-1", who is connected with "James", "Jane" and "Robert." Not only they meet the query labels but also interact with each other in an effective manner (with minimal costs)[32].

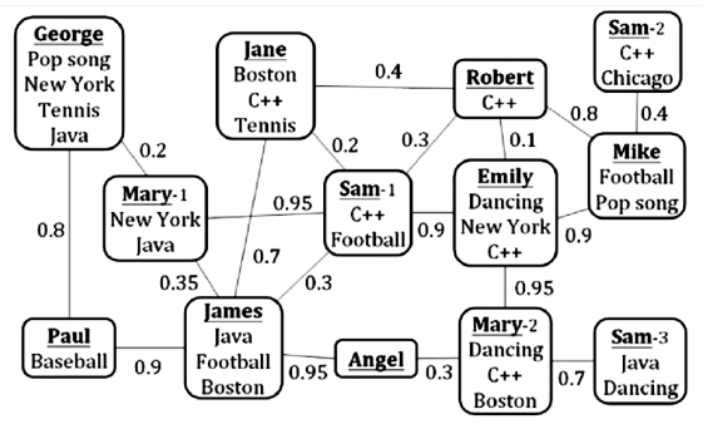

Figure 1. A social network with labels on each person. Labels include name, interest, skill, and hometown. Note that "number" to individuals to distinguish between people with the same name is appended[32].
This method shows that grouping-based method can reach the good quality of returned persons as a greedy search algorithm works at a considerable outperformance on the time efficiency and can use a lot of space in memory due to the usage of labels for each user[32].

Another method investigates personalized social search based on user's social relations - search results are re-ranked according to their relations with individuals in the user's social network. Carmel, D., et al; studied the effectiveness of several social network types for personalization: (1) Familiarity-

based network of people related to the user through explicit familiarity connection; (2) Similarity-based network of people "similar" to the user as reflected by their social activity; (3) Overall network that provides both relationship types. For comparison, authors experiment with Topic-based personalization that is based on the user's related terms, aggregated from several social applications. Carmel, D., et al; evaluate the contribution of the different personalization strategies by an off-line study and by a user survey within our organization. In the off-line study bookmarkbased evaluation was applied, suggested recently, that exploits data gathered from a social bookmarking system to evaluate personalized retrieval. In the on-line study the feedback of 240 employees exposed to the alternative personalization approaches were analyzed. Our main results show that both in the off-line study and in the user survey, social network based personalization significantly outperforms non-personalized social search. Additionally, as reflected by the user survey, all three SN-based strategies significantly outperform the Topicbased strategy. In this work the notion of social search has been used to describe the search process over "social" data gathered from Web 2.0 applications, such as social book-marking systems, wikis, blogs, forums, social network sites (SNSs) [36], and many others. Such a social search system represents different entity types (documents, people, communities, tags) and their interrelations, and allows searching for all object types related to the user's query[33].

As a summary we aim to analyze two methods in this section including context-based search and SN-based personalized social search. The first one returns a ranking list of people who possess the targeted name label and connects to other context labels with minimum communication costs through an effective sub graph in the social network[32]. And the latter uses on-line and off-line study to investigate personalized social search based on the user's social relations-search; In this method results are re-ranked according to their relations with individuals in the user's social network. The bookmark-based evaluation for search personalization has the advantage that can be easily applied in very large scales, without any user intervention[33] 
TABLE 2: PEOPLE SEARCH MECHANISM

\begin{tabular}{|c|c|c|c|}
\hline $\begin{array}{c}\text { Mechanis } \\
\text { m }\end{array}$ & Main idea & $\begin{array}{c}\text { Advantage } \\
\text { s }\end{array}$ & $\begin{array}{c}\text { Disadvantag } \\
\text { es }\end{array}$ \\
\hline $\begin{array}{c}\text { Context- } \\
\text { base search }\end{array}$ & $\begin{array}{c}\text { Returns a } \\
\text { ranking list } \\
\text { of people by } \\
\text { using query } \\
\text { labels. }\end{array}$ & $\begin{array}{c}\text { Has a good } \\
\text { performanc } \\
\text { e on the } \\
\text { time } \\
\text { efficiency. }\end{array}$ & $\begin{array}{c}\text { Uses a lot of } \\
\text { space in } \\
\text { memory. }\end{array}$ \\
\hline $\begin{array}{c}\text { SN-based } \\
\text { personalize } \\
\text { d social } \\
\text { search }\end{array}$ & $\begin{array}{c}\text { Investigate } \\
\text { personalized } \\
\text { social search } \\
\text { based on the } \\
\text { user's social } \\
\text { relations. }\end{array}$ & $\begin{array}{c}\text { It can be } \\
\text { easily } \\
\text { applied in } \\
\text { very large } \\
\text { scales. }\end{array}$ & $\begin{array}{c}\text { Suffers from } \\
\text { lower } \\
\text { quality. }\end{array}$ \\
& & \\
\hline
\end{tabular}

\section{Discovery of Web Services}

With the tremendous popularity of Web applications and the variety of handheld devices like PDA's and smart phones that allow people connect these applications, socializing over the Web is now an integral part of these people's daily lives.

In this section we first review the recent web service applications called LinkedWS which can be used in collaboration, substitution and etc. For instance, not only LinkedW Sassists service engineers expand existing compositions based on the recommendations of some Web services, but also helps make Web services highly available by identifying the most appropriate substitutes in case of failing Web services. Such a substitution is quite different from the existing approaches that promote replicated use of Web services and not semantically similar Web services. In the given implementation shown in the figure 2 , the recommendation/robustness-partnership social networks of a Web service was built so that different experiments were completed including the discovery of substitute and partner Web services along with the comparison of the LinkedWS performance with an UDDI registry implementation [37].

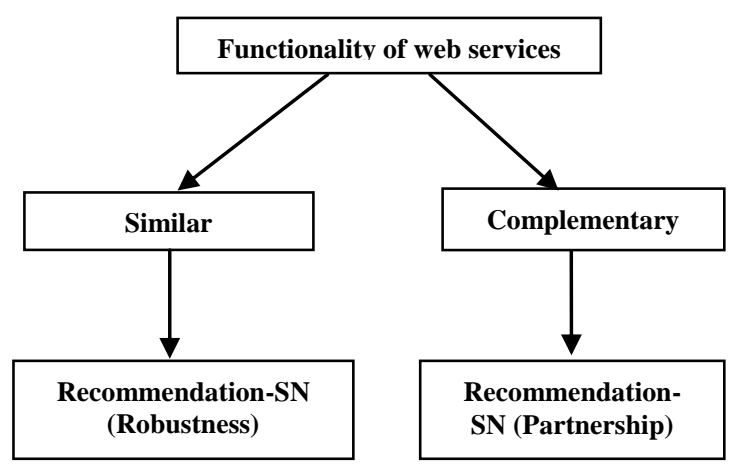

Figure 2. Social Network Categorization[37]
Another method is to break the similarity degree between Web services into clusters and record their reaction with experimental work through formulas to improve scalability and hope to expand the method by identifying the changes that affect social networks form which is shown in figure 3. A Web service that does not exist or an edge weight that drops below a certain threshold must be reflected on these networks [36].
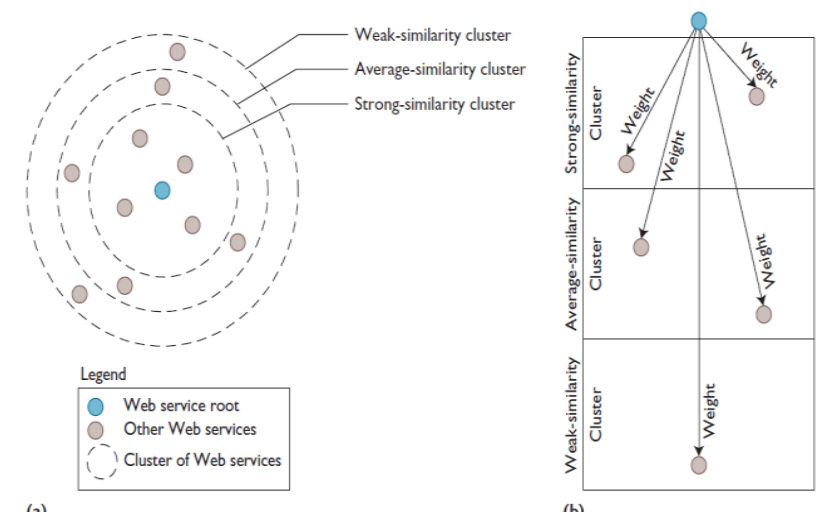

(b)

Figure 3. Social network management; author split the similarity degree between Web services in to (a) three clusters. While this clustering is in progress, Web services are (b) being connected within the social network [36].

In 2011, Maamar, Z., H. Hacid, and M.N. Huhns proposed a new method for web service discovery. Collaboration, Competition and Substitution are three ways for maintaining social networks which can be considered independently as a network of social behaviors. They can also be starting points of building more networks, depending on the interactions that lie between Web services such as delegation and supervision. Table 3 illustrates web service management strategies into four subsection as below [38]. 
TABLE 3. WEB SERVICE MANAGEMENT STRATEGIES [38].

\begin{tabular}{|c|c|c|c|}
\hline $\begin{array}{l}\text { Comparative } \\
\text { elements }\end{array}$ & Basic & Community & $\begin{array}{c}\text { Social } \\
\text { networks }\end{array}$ \\
\hline Description & $\begin{array}{c}\text { Web } \\
\text { Service } \\
\text { Description } \\
\text { developed } \\
\text { by provider } \\
\text { and then } \\
\text { made } \\
\text { available to } \\
\text { all users. }\end{array}$ & $\begin{array}{c}\text { Web service } \\
\text { description } \\
\text { made } \\
\text { available by } \\
\text { provider is } \\
\text { subjected to } \\
\text { enrichment } \\
\text { through } \\
\text { annotations } \\
\text { by } \\
\text { community } \\
\text { members and } \\
\text { then offered } \\
\text { to other } \\
\text { members for } \\
\text { use; enriched } \\
\text { description } \\
\text { might suffer } \\
\text { from } \\
\text { discrepancies. }\end{array}$ & $\begin{array}{l}\text { Web service } \\
\text { description } \\
\text { made } \\
\text { available by } \\
\text { provider is } \\
\text { subjected to } \\
\text { possible } \\
\text { enrichment } \\
\text { through } \\
\text { annotations } \\
\text { by members } \\
\text { of the same } \\
\text { social } \\
\text { network, } \\
\text { increasing } \\
\text { the enriched } \\
\text { description } \\
\text { acceptance } \\
\text { by the rest of } \\
\text { this social } \\
\text { network. }\end{array}$ \\
\hline Discovery & $\begin{array}{c}\text { Web } \\
\text { service } \\
\text { discovery } \\
\text { after } \\
\text { registry } \\
\text { screening. }\end{array}$ & $\begin{array}{l}\text { Web service } \\
\text { collective } \\
\text { discovery } \\
\text { after registry } \\
\text { screening and } \\
\text { discovery } \\
\text { outcomes are } \\
\text { shared with } \\
\text { other } \\
\text { community } \\
\text { members. }\end{array}$ & $\begin{array}{l}\text { Web service } \\
\text { discovery } \\
\text { after registry } \\
\text { screening is } \\
\text { driven by the } \\
\text { needs of each } \\
\text { social } \\
\text { network's } \\
\text { members. }\end{array}$ \\
\hline Composition & $\begin{array}{c}\text { Web } \\
\text { service } \\
\text { composition } \\
\text { is driven by } \\
\text { individual } \\
\text { users who } \\
\text { are familiar } \\
\text { with } \\
\text { composition } \\
\text { techniques } \\
\text { and } \\
\text { constraints. }\end{array}$ & $\begin{array}{l}\text { Web service } \\
\text { collective } \\
\text { composition } \\
\text { is driven by } \\
\text { some } \\
\text { community } \\
\text { members; } \\
\text { composition } \\
\text { outcomes are } \\
\text { shared with } \\
\text { other } \\
\text { members; } \\
\text { community } \\
\text { interests } \\
\text { prevail over } \\
\text { individual } \\
\text { interests. }\end{array}$ & $\begin{array}{l}\text { Web service } \\
\text { composition } \\
\text { is driven by } \\
\text { the needs and } \\
\text { previous } \\
\text { experiences } \\
\text { of each } \\
\text { social } \\
\text { network's } \\
\text { members. }\end{array}$ \\
\hline Trust & $\begin{array}{l}\text { Trust } \\
\text { directly is } \\
\text { established } \\
\text { between } \\
\text { user and } \\
\text { Web } \\
\text { service } \\
\text { provider. }\end{array}$ & $\begin{array}{l}\text { Web service } \\
\text { trusted by } \\
\text { members of } \\
\text { the } \\
\text { community is } \\
\text { based on past } \\
\text { experiences; } \\
\text { ranking } \\
\text { technique can } \\
\text { be used. }\end{array}$ & $\begin{array}{l}\text { Trust mainly } \\
\text { relates to the } \\
\text { strength of } \\
\text { the social } \\
\text { relations that } \\
\text { users have on } \\
\text { top of their } \\
\text { experiences } \\
\text { of Web } \\
\text { service use. }\end{array}$ \\
\hline
\end{tabular}

In 2011, Elnaffar, S. and Z. Maamar presented a new method that describes how to work on an optimization problem where the authors wish to select Web services that fulfill the required functions while 1are similar to each other functional-wise, and 2communicate with each other at them minimum cost. The functional similarity constraint adds reliability to the operation of the composite Web service in case one of the Web services fails. The communication cost is computed by measuring the social network diameter, which is the shortest path between any two nodes [39].Another method is the supervision value which was added to previous web service management and requires two types of nodes to represent the master and slave Web services and one type of edge to represent the supervision relationship[6].

\section{TABLE 4. VALUE ADDED TO WEB SERVICES MANAGEMENT[6].}

\begin{tabular}{|c|c|}
\hline $\begin{array}{l}\text { Social network } \\
\text { type }\end{array}$ & Value-added \\
\hline Supervision & $\begin{array}{l}\text { Assist Master web service to select } \\
\text { appropriate Slave web services in } \\
\text { response to users' requests. }\end{array}$ \\
\hline Competition & $\begin{array}{l}\text { Assist Master web service to find a } \\
\text { replacement to the Slave web service } \\
\text { that declined its composition request. }\end{array}$ \\
\hline Substitution & $\begin{array}{l}\text { Assist Master web service to achieve } \\
\text { business process continuity when a } \\
\text { Slave web service fails. }\end{array}$ \\
\hline Collaboration & $\begin{array}{l}\text { Assist Master web service to improve } \\
\text { composition quality. }\end{array}$ \\
\hline Recommendation & $\begin{array}{l}\text { Assist Master web service to develop } \\
\text { highly-compatible compositions. }\end{array}$ \\
\hline
\end{tabular}

As a summary in this section we go through 4 methods; LinkedWS expands existing compositions based on the recommendations of some Web services, but also helps make Web services highly available by identifying the most appropriate substitutes in case Web services fail[40].Second one breaks the similarity degree between Web services into clusters and records their reactions with experimental work through formulas to improve scalability in a large scale [37]. The third one, Composite Web Service Builder Algorithm selects web services that fulfill the required functions while they are similar to each other functional-wise, and communicate with each other at the minimum cost [39]. The forth one, added trust value to web service management strategies, which is a big challenge in their own kind, to improve selection between web services in case of lacking time [38]. The last one uses the Web Services as either master or slave in order to capture all interactions that occur between web services locating in the same or separate communities. The interactions are supervision, substitution, competition, collaboration, and recommendation [6]. 
TABLE 5. THE WEB SERVICES DISCOVERY MECHANISMS

\begin{tabular}{|c|c|c|c|}
\hline $\begin{array}{c}\text { Mechanis } \\
\text { m }\end{array}$ & Main idea & Advantages & $\begin{array}{c}\text { Disadvantage } \\
\mathrm{s}\end{array}$ \\
\hline LinkedWS & $\begin{array}{c}\text { Merges, } \\
\text { substitute } \\
\text { different } \\
\text { web } \\
\text { services } \\
\text { into } \\
\text { compositio } \\
\text { n. }\end{array}$ & $\begin{array}{l}\text { Expands } \\
\text { existing } \\
\text { compositions } \\
\text { based on the } \\
\text { recommendati } \\
\text { ons; identifies } \\
\text { the most } \\
\text { appropriate } \\
\text { substitutes in } \\
\text { case the web } \\
\text { services fail. }\end{array}$ & $\begin{array}{c}\text { Implementatio } \\
\text { ns have not } \\
\text { been used in } \\
\text { practical } \\
\text { fields. }\end{array}$ \\
\hline $\begin{array}{c}\text { Social } \\
\text { Networks } \\
\text { for Web } \\
\text { Services } \\
\text { Discovery }\end{array}$ & $\begin{array}{l}\text { Uses social } \\
\text { networks } \\
\text { for web } \\
\text { service } \\
\text { discovery. }\end{array}$ & $\begin{array}{c}\text { Improves } \\
\text { scalability } \\
\text { and } \\
\text { implementatio } \\
\text { ns are based } \\
\text { on } \\
\text { experimental } \\
\text { work. }\end{array}$ & $\begin{array}{l}\text { Scalability } \\
\text { does not affect } \\
\text { navigation and } \\
\text { discovery } \\
\text { mechanism. }\end{array}$ \\
\hline $\begin{array}{c}\text { Composite } \\
\text { Web } \\
\text { Service } \\
\text { Builder } \\
\text { Algorithm }\end{array}$ & $\begin{array}{l}\text { Selects an } \\
\text { effective } \\
\text { set of Web } \\
\text { services } \\
\text { that can } \\
\text { collaborate } \\
\text { in order to } \\
\text { attain to the } \\
\text { composite } \\
\text { Web } \\
\text { service. }\end{array}$ & $\begin{array}{l}\text { Secures all } \\
\text { the functions } \\
\text { required by } \\
\text { the composite } \\
\text { Web service } \\
\text { minimizing } \\
\text { the } \\
\text { communicatio } \\
\text { n overhead. }\end{array}$ & $\begin{array}{l}\text { Implementatio } \\
\mathrm{n} \text { is a work in } \\
\text { progress not in } \\
\text { real test bed. }\end{array}$ \\
\hline
\end{tabular}

\section{Results and Comparisons}

As we mentioned in people search in section 3 , given a labeled social network and a set of query labels consisting of a targeted label and other context labels, we aim to return a ranking list of individuals who possess the targeted name label and connects to other context labels with minimum communication costs through certain effective sub graph; experiments on the bibliography data demonstrate the excellent quality of our found ranked results and takes significantly less execution time comparing to a greedy approximation algorithm[32]. In other protocols, results show that there are several substantial discrepancies between the two evaluation methods. In particular, according to the offline study the, overall network is inferior to the similarity and familiarity networks, and to the Topicbased strategy, while in contrast, according to the user survey, the overall network performs the best. In both cases these types of personal queries are limited and do not cover the whole spectrum of possible personal queries, but rather a subset that is likely to benefit from personalization and which can be judged by the methods in use[33]. Having discussed about keyword search in section 2, we reviewed some methods one of which is T-
DHT algorithm. Except T-DHT, the current solutions neither solve the keyword search problem efficiently in a scalable way, nor avoid hot spots appearance when popular keywords are used[31].Another one is Heap Union, a novel query processing operator that efficiently supports skipping over unions of sorted inputs. Heap Union improves query processing efficiency with a factor between 1.12 and 2.36 in our system. With this foundation in place, we have the basis for extensions to more advanced ranking functions such as ranking based on network-centric properties in social networks while enforcing access control [30].

Section 4 included a discovery through web services, LinkedWS that permits addressing different needs. For example, LinkedWS helps service Engineers expand existing compositions based on the recommendations of some Web services. It also, helps make Web services highly available by identifying the most appropriate substitutes in case of web service failure. This kind of substitution is quite different from the existing approaches that promote replicated use of Web services and semantically different Web services. In term of implementation we built the recommendation/robustness-partnership social networks of a Web service so that different experiments were completed including the discovery of substitute and partner Web services along with comparison of the LinkedWS performance with an UDDI registry implementation. The performance of LinkedWS is absolutely better than previous discovery UDDI model, especially in consistency field[40]. Splitting the similarity degree between Web services into clusters and record their reaction with experimental work and by formulas were discussed, by this the authors improve scalability but hope to expand the method by identifying the changes that affect social networks shape and how they are formed. A Web service that ceases to exist or an edge weight that drops below a certain threshold must be reflected on these networks[37].To improve the LinkedWS and to insert trust issue, the authors defined a new framework that is way better than the previous mechanisms. In addition, Supervision as a value was added to Web services management which adopted a master-slave model to structure the community and regulate the functionality of the Web services in the social network [6].

\section{Conclusion and Future Works}

A social network is a useful theoretical construction in the social sciences to study relationships between individuals, groups, organizations, or even entire societies (social units, see differentiation).This paper examined social networks as a new multidisciplinary research filed that bridges social search and introduces the most important aspects of social networks by considering four main aspects: people search, job search, keyword search and web service discovery also we reviewed the past and the state of the searching and web 
service discovery in social network up to now. In each of subsets we reviewed the mechanisms of keyword search in syntax-based, which is considered as a big disadvantage for current networks; we should try to put the case into semantic-base search that is more useful especially regarding today's advanced technologies. Also this case is true for people search. these mechanisms we reviewed are also useful in so many fields but it's better to focus on semantic-base search. In web service discovery five mechanisms inserted into WS management that was very useful in order to substitute web services in case of failure but we could also add several mechanisms such as priority and delegation into previous ones in the future that improves selection between web services in case of failure. LinkedWS performs absolutely better than previous discovery UDDI model specially in consistency field, it's better to consider trust issue in social networks in future [39]. Our future research would be designing a better Web services discovery protocol which would take into account Web services' social qualities as input besides their functional and non-functional properties [6]. In the paper about scalable tag search, authors hope that T-DHT algorithm could solve typical Peer-to-Peer keyword search problems too, even though the implementation seems difficult since one should have access to identifier key directly throughout the search process while in social networks these search applications are defined in a set of where the authors did not have access to them before [31].In the paper about people search authors use context-base search. We think in future we can use syntax-based model [40] to define each person to improve the searching result and to speed up the search [32]. In the future work it is better to expand personalized social search study to other types of personal queries, to better understand what types of queries should be personalized, and for the long run, to enhance this personalized social search system to be able to decide on-line, per each user and query pair, the most suitable search policy [33].

\section{References}

[1] Boyd, D.M. and N.B. Ellison, Social network sites:definition, history, and scholarship. Engineering Management Review, IEEE, 2010. 38(3): p. 16-31.

[2] Mark-Shane, S., Facebook as a social search engine and the implications for libraries in the twenty-first century. Emerald, 2008. 26(0): p. 540 556.

[3] Hughes, D.J., et al., A tale of two sites: Twitter vs. Facebook and the personality predictors of social media usage. Computers in Human Behavior, 2012. 28(2): p. 561-569.

[4] Nettleton, D.F., Data mining of social networks represented as graphs. Computer Science Review, 2013. 7(0): p. 1-34.

[5] Koskinen, J.H., G.L. Robins, and P.E. Pattison, Analysing exponential random graph (p-star) models with missing data using Bayesian data augmentation. Statistical Methodology, 2010. 7(3): p. 366-384.

[6] Yahyaoui, H., et al., Towards a community-based, social network-driven framework for Web services management. Future Generation Computer Systems, 2013. 29(6): p. 1363-1377.

[7] Clements, M., A.P. de Vries, and M.J.T. Reinders, The influence of personalization on tag query length in social media search. Information Processing \& Management, 2010. 46(4): p. 403412.

[8] Kim, H.-N., et al., Folksonomy-based personalized search and ranking in social media services. Information Systems, 2012. 37(1): p. 61-76.

[9] Faust, K., A puzzle concerning triads in social networks: Graph constraints and the triad census. Social Networks, 2010. 32(3): p. 221-233.

[10] Zhang, X., et al., Social image tagging using graphbased reinforcement on multi-type interrelated objects. Signal Processing, 2013. 93(8): p. 21782189.

[11] Han, L. and H. Yan, BSN: An automatic generation algorithm of social network data. J. Syst. Softw., 2011. 84(8): p. 1261-1269.

[12] Afshar-Nadjafi, B., A. Rahimi, and H. Karimi, A genetic algorithm for mode identity and the resource constrained project scheduling problem. Scientia Iranica, (0).

[13] Xu, K. and X. Zhang, Mining Community in Mobile Social Network. Procedia Engineering, 2012. 29(0): p. 3080-3084.

[14] Ajami, R., N.A. Qirim, and N. Ramadan, Privacy Issues in Mobile Social Networks. Procedia Computer Science, 2012. 10(0): p. 672-679.

[15] Chang, C., S.N. Srirama, and S. Ling, Towards an adaptive mediation framework for Mobile Social Network in Proximity. Pervasive and Mobile Computing, (0).

[16] Eirinaki, M., S. Pisal, and J. Singh, Feature-based opinion mining and ranking. Journal of Computer and System Sciences, 2012. 78(4): p. 1175-1184.

[17] Kandiah, V. and D.L. Shepelyansky, PageRank model of opinion formation on social networks. Physica A: Statistical Mechanics and its Applications, 2012. 391(22): p. 5779-5793.

[18] Corsaro, D., et al., Actor network pictures and networking activities in business networks: An experimental study. Industrial Marketing Management, 2011. 40(6): p. 919-932.

[19] Kahar, R., et al., Trusting the Social Media in Small Business. Procedia - Social and Behavioral Sciences, 2012. 66(0):p. 564-570.

[20] Kolberg, M., et al., Feature interaction in a federated communications-enabled collaboration platform. Computer Networks, (0).

[21] Ducatelle, F., G. Caro, and L. Gambardella, An Analysis of the Different Components of the AntHocNet Routing Algorithm, in Ant Colony Optimization and Swarm Intelligence, M. Dorigo, 
et al., Editors. 2006, Springer Berlin Heidelberg. p. 37-48.

[22] Erola, A., et al., Exploiting social networks to provide privacy in personalized web search. Journal of Systems and Software, 2011. 84(10): p. 1734-1745.

[23] Yang, S.J.H., et al., Improving peer-to-peer search performance through intelligent social search. Expert Systems with Applications, 2009. 36(7): p. 10312-10324.

[24] Zaharieva, A., Social welfare and wage inequality in search equilibrium with personal contacts. Labour Economics, 2013. 23(0): p. 107-121.

[25] Liu, D., et al., Types of stable network structures based on exhaustive search. Social Networks, 2013. 35(1): p. 124-129.

[26] Zhang, Z., et al., User community discovery from multi-relational networks. Decision Support Systems, 2013. 54(2): p. 870-879.

[27] del Val, E., M. Rebollo, and V. Botti, Promoting cooperation in service-oriented MAS through social plasticity and incentives. Journal of Systems and Software, 2013. 86(2): p. 520-537.

[28] Jung, J.J., Trustworthy knowledge diffusion model based on risk discovery on peer-to-peer networks. Expert Systems with Applications, 2009. 36(3, Part 2): p. 7123-7128.

[29] Liu, L., et al., A probabilistic graphical model for topic and preference discovery on social media. Neurocomputing, 2012. 95(0): p. 78-88.

[30] Bj, T.A., et al., Workload-aware indexing for keyword search in social networks, in Proceedings of the 20th ACM international conference on Information and knowledge management2011, ACM: Glasgow, Scotland, UK. p. 535-544.

[31] Mozo, A. and J. Salvachúa, Scalable tag search in social network applications. Computer Communications, 2008. 31(3): p. 423-436.

[32] Li, C.-T., M.-K. Shan, and S.-D. Lin, Contextbased people search in labeled social networks, in Proceedings of the 20th ACM international conference on Information and knowledge management2011, ACM: Glasgow, Scotland, UK. p. $1607-1612$.

[33] Carmel, D., et al., Personalized social search based on the user's social network, in Proceedings of the 18th ACM conference on Information and knowledge management2009, ACM: Hong Kong, China. p. 1227-1236.

[34] Fedotova, N. and L. Veltri, Reputation management algorithms for DHT-based peer-topeer environment. Computer Communications, 2009. 32(12): p. 1400-1409.

[35] Jafari Navimipour, N., et al., Resource discovery mechanisms in grid systems: A survey. Journal of Network and Computer Applications, 2014.

[36] $\mathrm{Xu}, \mathrm{C}$., et al., It is not for fun: An examination of social network site usage. Information \& Management, 2012. 49(5): p. 210-217.
[37] Maamar, Z., et al., Using Social Networks for Web Services Discovery. Internet Computing, IEEE, 2011. 15(4): p. 48-54.

[38] Maamar, Z., H. Hacid, and M.N. Huhns, Why Web Services Need Social Networks. Internet Computing, IEEE, 2011. 15(2): p. 90-94.

[39] Elnaffar, S. and Z. Maamar, Composite Web Services Formation Using a Social Network of Web Services: A Preliminary Investigation. Procedia Computer Science, 2011. 5(0): p. 466-471.

[40] Maamar, Z., et al., LinkedWS: A novel Web services discovery model based on the Metaphor of "social networks". Simulation Modelling Practice and Theory, 2011. 19(1): p. 121-132.

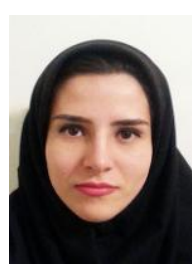

Shabnam Hassanzadeh sharif: is a M.Sc. student in Department of Computer Engineering, East Azarbaijan Science and Research Branch, Islamic Azad University, Tabriz, Iran since 2012. She received her B.S. degree in computer engineering (software) from Islamic Azad University, Tabriz, Iran, 2010. Her current research interests are focused on wireless sensor actor networks and social network.

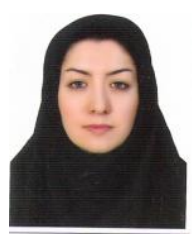

Shabnam Mahmazi: is a M.Sc. student in Department of Computer Engineering, East Azarbaijan Science and Research Branch, Islamic Azad University, Tabriz, Iran since 2012. She received her B.S. degree in computer engineering (software) from Islamic Azad University, Ahar, Iran, 2011. Her current research interests are focused on pervasive computing and social network.

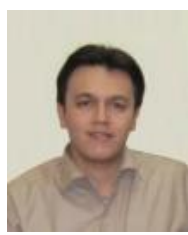

Nima Jafari Navimipour received his B.S. in computer engineering, software engineering, from Tabriz Branch, Islamic Azad University, Tabriz, Iran, in 2007. the M.S. in computer engineering, computer architecture, from Tabriz Branch, Islamic Azad University, Tabriz, Iran, in 2009. From 2011, he is a Ph.D student in Science and Research Branch, Islamic Azad University, Tehran, Iran. Currently he is Lecturer in Department of Computer Engineering, East Azarbaijan Science and Research Branch, Islamic Azad University, Tabriz, Iran. He has published more than 50 papers in various journals and conference proceedings. His research interests include Cloud/Grid Systems, Traffic Control, Social Networks, Computational Intelligence, Evolutionary Computing, and Wireless Networks. 
Behzad Farid Aghdam received his B.S. in Translation Studies from university college of Nabi Akram Tabriz, Iran, in 2008. Currently he is a M.Sc. student in Department of Computer Engineering, East Azarbaijan Science and Research Branch, Islamic Azad University, Tabriz, Iran since 2012. His research interests include Web Services, Cloud Computing, Network Security and Wireless Networks. 